\title{
Possible reduction of earthquake hazard on the Wellington Fault, New Zealand, after the nearby 1855, $M$ 8.2 Wairarapa earthquake and implication for interpreting paleoearthquake intervals
}

\author{
Zhujun Han \\ Institute of Geology, China Seismological Bureau, Beijing, China
}

\begin{abstract}
Based on the indicative modelling, the changes in Coulomb failure function ( $\triangle \mathrm{CFS}$ ) suggest that the W-HV segment and the T-P segment could be stable in at least the future 300 years and 190 years respectively, for these periods should be needed to accumulate the stress released by the $M 8.2$ Wairarapa earthquake, assuming that there is no influence from other sources, the earthquake did not alter the failure threshold, and that failure is a fairly deterministic process. The results also show that the influence on the W-HV segment and T-P segment of the Wellington Fault caused by the 1855, M 8.2 Wairarapa earthquake is significant considering that the average fault rupture recurrence interval on the Wellington Fault is about 500-770 years. With our present understanding of the Wellington and Wairarapa faults, it can be concluded that the 1855 Wairarapa earthquake retarded earthquake occurrence on the W-HV segment and the T-P segment of the Wellington Fault. Thus the seismic hazard in the Wellington region may be over-estimated.
\end{abstract}

Key words Wellington region - changes on Coulomb failure stress - earthquake hazard

\section{Introduction}

There are now many international examples that demonstrate that static stress changes, generated by large earthquakes, influence the timing and locations of subsequent earthquakes (Harris, 1998; Stein, 1999). The changes in stress can promote or trigger earthquake occurrence and cause the clustering of large events in space and time (Harris and Simpson, 1992; King et al.,

Mailing address: Dr. Zhujun Han, Institute of Geology, China Seismological Bureau, Beijing 100029, China; e-mail: zhujunh@btamail.net.cn
1994; Stein et al., 1994; Robinson and Benites, 1996; Deng and Sykes, 1997; McGinty and Darby, 2001). Paleoseismological studies also demonstrate that the clustering of large events has occurred widely (Sieh et al., 1989; McCalpin and Nishenko, 1996). On the other hand, earthquakes can also be delayed or prevented by static stress changes. The great 1906 San Francisco earthquake ruptured the San Andreas Fault in Central and Northern California, and generated a stress shadow for all faults of similar orientation (strike) and slip direction (rake) (Harris and Simpson, 1998). The stress shadow has dominated the San Francisco Bay area for decades (Simpson and Reasenberg, 1994). The record of only four $M \geq 6$ earthquakes in the 78 years after 1906 is in marked contrast to the record of $18 M \geq 6$ earthquakes in the 71 years leading to the great San Francisco earth- 
quake (Ellsworth, 1990; Jaume and Sykes, 1996).

A large earthquake with magnitude 8.2 occurred on the Wairarapa Fault in 1855 in the Wellington region, New Zealand. Horizontal displacement during the 1855 Wairarapa earthquake was dominant (Wellman, 1955). This suggests that the 1855 Wairarapa earthquake may have created a stress shadow on subparallel strike-slip faults with similar rakes in the Wellington region. As a consequence of oblique subduction of the Pacific plate beneath the Australian plate at $\sim 40 \mathrm{~mm} / \mathrm{yr}$ at an azimuth of $265^{\circ}$ at the latitude of Wellington, several active right-lateral strike-slip faults have developed in the Wellington region (fig. 1a,b). They have a strike of approximately $225^{\circ}$. This tectonic setting implies that earthquakes pose a serious natural hazard in the Wellington region (Van Dissen and Berryman, 1996), especially considering that most population centers in the Wellington region, encompassing about 400000 people ( $10 \%$ of the country's population), are within $10 \mathrm{~km}$ of one of the active strike-slip faults. By applying synthetic seismicity models to the Wel-

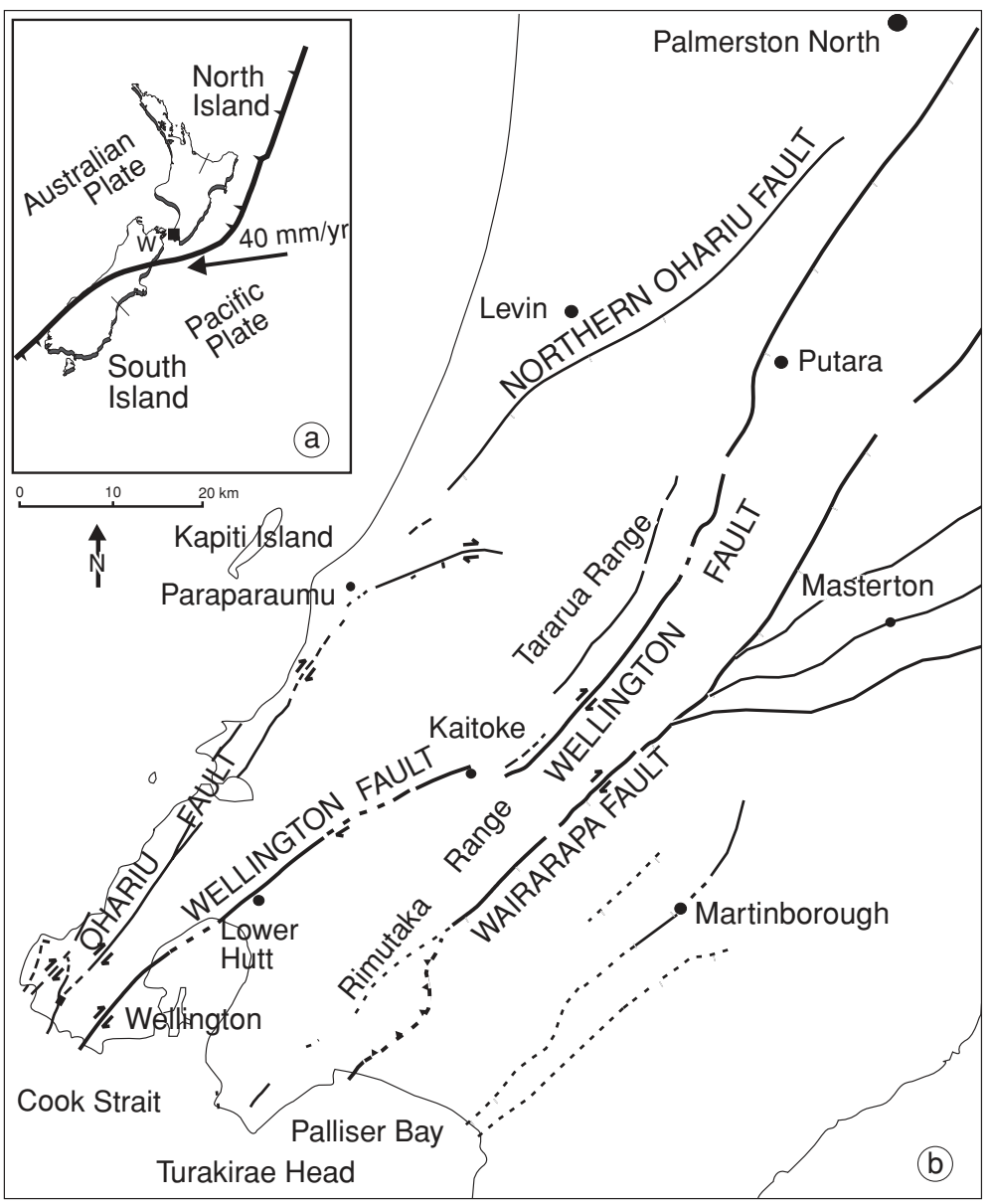

Fig. 1a,b. a) Oblique subduction of the Pacific plate beneath the Australian plate at $\sim 40 \mathrm{~mm} / \mathrm{yr}$ at an azimuth of $265^{\circ}$ at the latitude of Wellington (W). b) The main active faults in the Wellington region. 

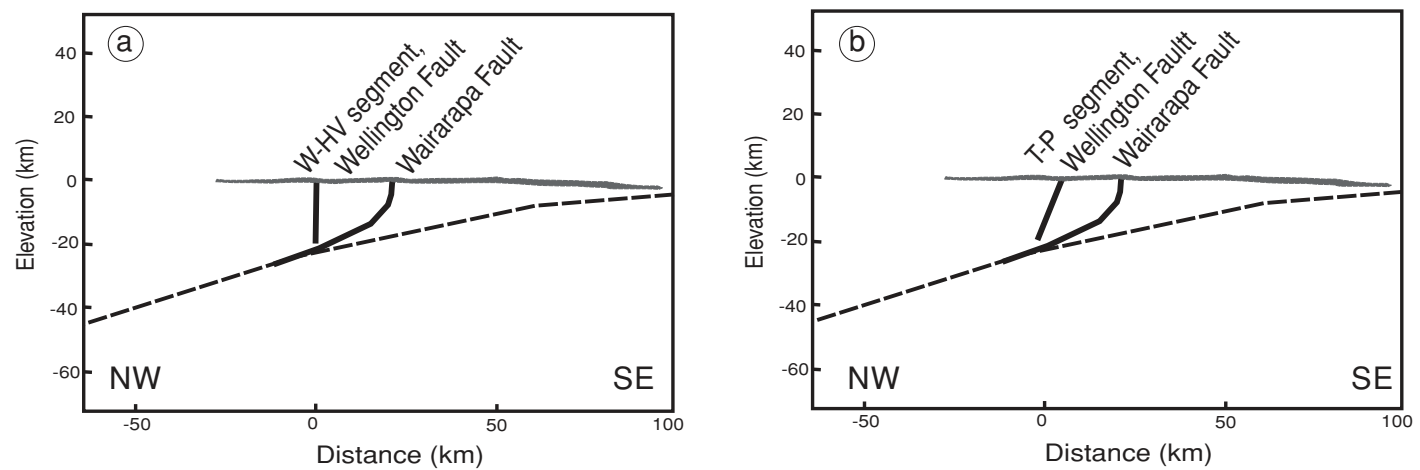

Fig. 2a,b. A listric Wairarapa Fault Model with a NW dip (modified from Darby and Beanland, 1992). The deepest segment is taken to extend tangentially from the modeled subduction interface at a depth of $25 \mathrm{~km}$. A vertical dip for the W-H segment (a) and a $70^{\circ}$ dip to the northwest for the T-P segment (b) are assumed (Russ J. Van Dissen, personal communication). Depth to bottom of the Wellington Fault or seismogenic thickness is assigned as $20 \mathrm{~km}$.

lington region and generating catalogs of 200000 years duration each, Robinson and Benites (1996) concluded that mutual inhibition mostly occurs between the subparallel strike-slip faults. The occurrence of the 1855 Wairarapa earthquake should have had great influence on its adjacent faults, subparallel in strike. It is important to estimate this influence in order to evaluate the seismic hazards in the Wellington region.

This paper will try to address the following questions: 1) the effect of the 1855 Wairarapa earthquake on the Wellington Fault in terms of the changes in Coulomb failure function $(\Delta \mathrm{CFS})$ in both amplitude and sign; 2) what kinds of indications, retardation or advancement, do the modelling results provide to events on the Wellington Fault? This indication is helpful for seismic hazard evaluation on the Wellington Fault.

\section{The Wairarapa Fault and the Wellington Fault}

\subsection{The Wairarapa Fault}

Darby and Beanland (1992) attempted to model the (limited) data on surface deformation due to the 1855 Wairarapa $M 8.2$ earthquake and suggested that a listric Wairarapa Fault was possible, the dip (to the NW) becoming progressively less steep at depth (fig. 2a,b). The listric Wairarapa Fault Model for computational simplicity is approximated by a sequence of five planar segments of increasing dip towards the surface, all with the same length of $130 \mathrm{~km}$ (table I, figs. 2a,b and 3). The deepest segment is taken to extend tangentially from the subduction interface at a depth of $25 \mathrm{~km}$. In this model, dextral slip of $12 \mathrm{~m}$ and reverse slip of $3 \mathrm{~m}$ are assigned. The listric Wairarapa Fault Model provides a very good fit to the regional data in terms of uplift and tilting northwest of the fault and almost no deformation to the southeast.

Grapes and Downes (1997) plotted the dextral and vertical displacement data of the 1855 earthquake from Turakirae Head in the SW to Mauriceville in the NE, a length of $100 \mathrm{~km}$. The results show that from Pigeon Bush to Turakirae Head, the horizontal displacement decreases southward and from Waiohine River and Kaipaitangata Stm to Mauriceville, the horizontal displacement decreases northward. Generally, the horizontal displacement has the feature of decreasing towards the rupture ends. Based on this feature of horizontal displacement along the 1855 earthquake rupture, each segment 
Table I. Model parameters for the 1855 Wairarapa earthquake (modified from Darby and Beanland, 1992).

\begin{tabular}{|c|c|c|c|c|c|c|c|c|c|c|}
\hline \multirow[t]{2}{*}{ Fault segment } & \multirow{2}{*}{$\begin{array}{l}\text { Length } \\
(\mathrm{km})\end{array}$} & \multirow{2}{*}{$\begin{array}{c}\text { Width } \\
\mathrm{km}\end{array}$} & \multirow{2}{*}{$\begin{array}{l}\text { Bottom } \\
\text { depth } \\
(\mathrm{km})\end{array}$} & \multirow{2}{*}{ Strike } & \multirow{2}{*}{$\begin{array}{l}\text { Dip/dip } \\
\text { direction } \\
\left({ }^{\circ}\right)\end{array}$} & \multicolumn{2}{|c|}{ Central location } & \multirow{2}{*}{$\operatorname{Rake}\left({ }^{\circ}\right)$} & \multirow{2}{*}{$\begin{array}{l}\text { Strike } \\
\operatorname{slip}(\mathrm{m})\end{array}$} & \multirow{2}{*}{$\begin{array}{l}\text { Dip } \\
\text { slip } \\
\text { (m) }\end{array}$} \\
\hline & & & & & & Latitude $\left({ }^{\circ}\right)$ & Longitude $\left({ }^{\circ}\right)$ & & & \\
\hline \multicolumn{11}{|c|}{ Listric Wairarapa Fault } \\
\hline Upper segment & 130 & 4 & 4.0 & 225 & 90 & -41.206 & 175.205 & 166 & 12.0 & 3.0 \\
\hline Segment 2 & 130 & 3.2 & 7.0 & 225 & $70 / 315$ & -41.2 & 175.2 & 166 & 12.0 & 3.0 \\
\hline Segment 3 & 130 & 7.8 & 13.0 & 225 & $50 / 315$ & -41.18 & 175.173 & 166 & 12.0 & 3.0 \\
\hline Segment 4 & 130 & 17.0 & 21.5 & 225 & $30 / 315$ & -41.12 & 175.09 & 166 & 12.0 & 3.0 \\
\hline $\begin{array}{r}\text { Segment } 5 \\
\text { (Deepest) }\end{array}$ & 130 & 10.2 & 25.0 & 225 & $20 / 315$ & -41.043 & 174.988 & 166 & 12.0 & 3.0 \\
\hline \multicolumn{11}{|c|}{ Tapered displacement Wairarapa Fault } \\
\hline $\begin{array}{l}\text { Upper segment, } \\
13 \text { patches along } \\
\text { the strike } \\
\text { direction }\end{array}$ & $10(\mathrm{~km}) \times 13$ & 4 & 4.0 & 225 & 90 & -41.206 & 175.205 & 166 & $\begin{array}{l}\text { See } \\
\text { table II }\end{array}$ & $\begin{array}{l}\text { See } \\
\text { table II }\end{array}$ \\
\hline $\begin{array}{l}\text { Segment } 2 \text {, } \\
13 \text { patches along } \\
\text { the strike } \\
\text { direction }\end{array}$ & $10(\mathrm{~km}) \times 13$ & 3.2 & 7.0 & 225 & $70 / 315$ & -41.2 & 175.2 & 166 & $\begin{array}{c}\text { See } \\
\text { table II }\end{array}$ & $\begin{array}{l}\text { See } \\
\text { table II }\end{array}$ \\
\hline $\begin{array}{l}\text { Segment } 3 \text {, } \\
13 \text { patches along } \\
\text { the strike } \\
\text { direction }\end{array}$ & $10(\mathrm{~km}) \times 13$ & 7.8 & 13.0 & 225 & $50 / 315$ & -41.18 & 175.173 & 166 & $\begin{array}{c}\text { See } \\
\text { table II }\end{array}$ & $\begin{array}{c}\text { See } \\
\text { table II }\end{array}$ \\
\hline $\begin{array}{l}\text { Segment } 4, \\
13 \text { patches along } \\
\text { the strike } \\
\text { direction }\end{array}$ & $10(\mathrm{~km}) \times 13$ & 17.0 & 21.5 & 225 & $30 / 315$ & -41.12 & 175.09 & 166 & $\begin{array}{c}\text { See } \\
\text { table II }\end{array}$ & $\begin{array}{l}\text { See } \\
\text { table II }\end{array}$ \\
\hline $\begin{array}{l}\text { Segment } 5 \text {, } \\
13 \text { patches along } \\
\text { the strike } \\
\text { direction }\end{array}$ & $10(\mathrm{~km}) \times 13$ & 10.2 & 25.0 & 225 & $20 / 315$ & -41.043 & 174.988 & 166 & $\begin{array}{c}\text { See } \\
\text { table II }\end{array}$ & $\begin{array}{c}\text { See } \\
\text { table II }\end{array}$ \\
\hline \multicolumn{11}{|c|}{ Flexed Wairarapa Fault } \\
\hline $\begin{array}{l}\text { Southern } \\
\text { segment. }\end{array}$ & 21 & 21.9 & 19 & 225 & $60 / 315$ & -41.462 & 174.866 & 175 & 12.0 & 1.0 \\
\hline Segment 2 & 3 & 10.9 & 9.5 & 220 & $61 / 310$ & -41.403 & 174.987 & 166 & 11.7 & 2.9 \\
\hline Segment 3 & 2 & 21.5 & 19 & 212 & $62 / 302$ & -41.375 & 174.978 & 162 & 11.5 & 3.7 \\
\hline Segment 4 & 2 & 10.7 & 9.5 & 203 & $64 / 293$ & -41.375 & 175.012 & 149 & 10.4 & 6.2 \\
\hline Segment 5 & 3 & 20.5 & 19 & 192 & $68 / 282$ & -41.352 & 175.0 & 148 & 10.3 & 6.3 \\
\hline Segment 6 & 2 & 20.1 & 19 & 203 & $71 / 293$ & -41.324 & 175.019 & 154 & 10.9 & 5.2 \\
\hline Segment 7 & 3 & 19.8 & 19 & 212 & $74 / 302$ & -41.303 & 175.046 & 165 & 11.6 & 3.2 \\
\hline Segment 8 & 2 & 19.7 & 19 & 220 & $75 / 310$ & -41.282 & 175.066 & 173 & 12.0 & 1.4 \\
\hline $\begin{array}{l}\text { Northern } \\
\text { segment. }\end{array}$ & 81 & 19.7 & 19 & 225 & $75 / 315$ & -41.016 & 175.413 & 175 & 12.0 & 1.0 \\
\hline
\end{tabular}




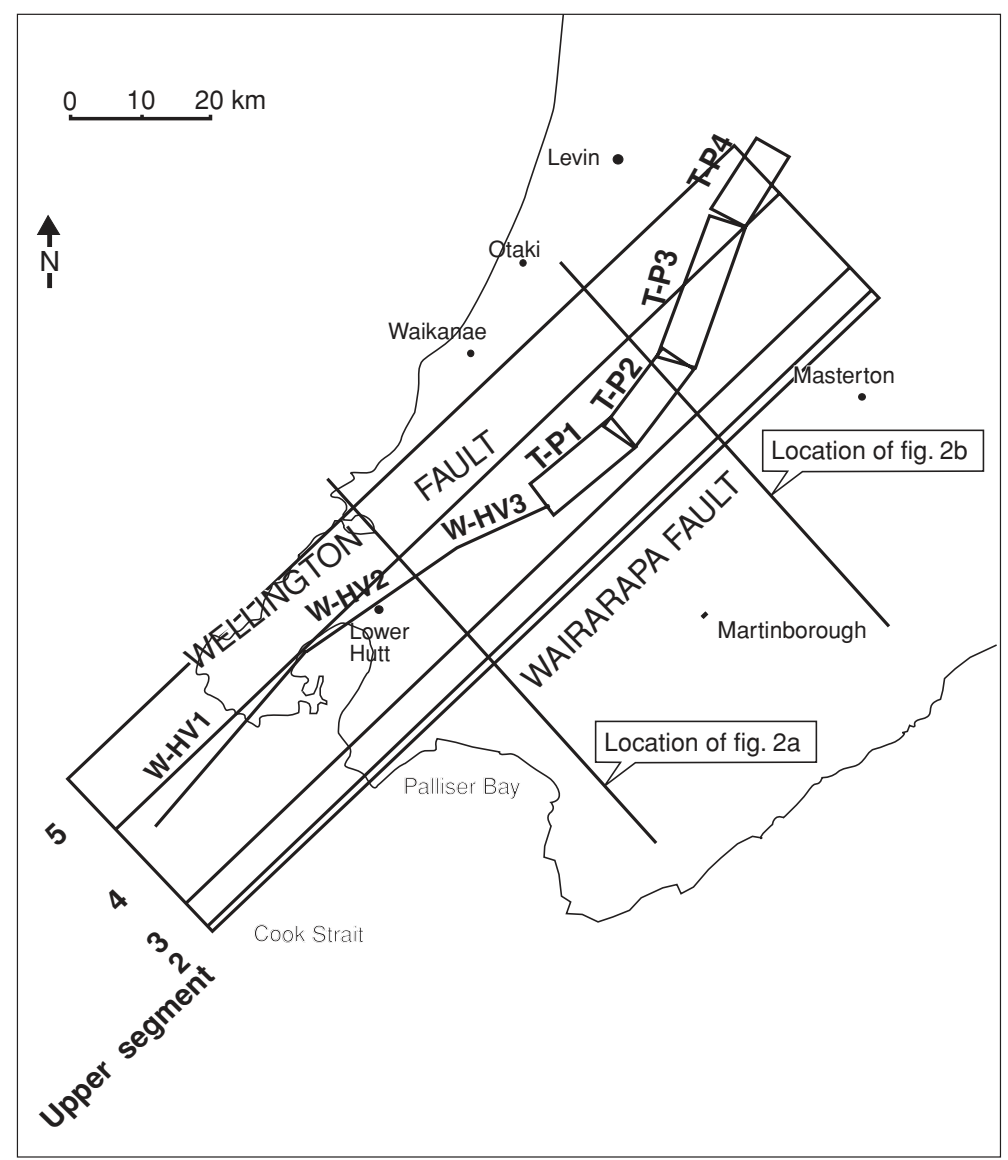

Fig. 3. The surface projections of the Wairarapa Fault, and the W-HV segment and T-P segment of the Wellington Fault. The listric Wairarapa Fault for computational simplicity is approximated by a sequence of five planar segments of increasing dip upward, all with the same length of $130 \mathrm{~km}$ (Darby and Beanland, 1992).

of the Wairarapa Fault can be subdivided into 13 equal-sized, rectangular patches along the strike direction and the slip is linearly tapered from a maximum of $12 \mathrm{~m}$ horizontal displacement and $3 \mathrm{~m}$ vertical displacement at the center to $1.71 \mathrm{~m}$ and 0.43 at the ends (fig. 4 , table I and II). Other parameters about the segments are kept the same as the listric Wairarapa fault model.

However, the vertical displacement increases rapidly to 4-6 $\mathrm{m}$ near Turakirae Head (Grapes and Downes, 1997). At the central section of the 1855 earthquake rupture, the vertical displacement is between 1 to $2 \mathrm{~m}$. North of Kaipaitangata Stream, it is less than $1 \mathrm{~m}$. This feature may be related to the variation of fault structure along strike. The offshore extension of the Wairarapa Fault appears to be offset about 8 $\mathrm{km}$ from its onshore position. Within the overlap region, an anticlinal fold was mapped by Grapes and Wellman (1988). Such features are consistent with a left step in a right-lateral strike-slip fault. Darby and Beanland (1992) modeled the fault as having effectively a straight bottom edge along the subduction inter- 


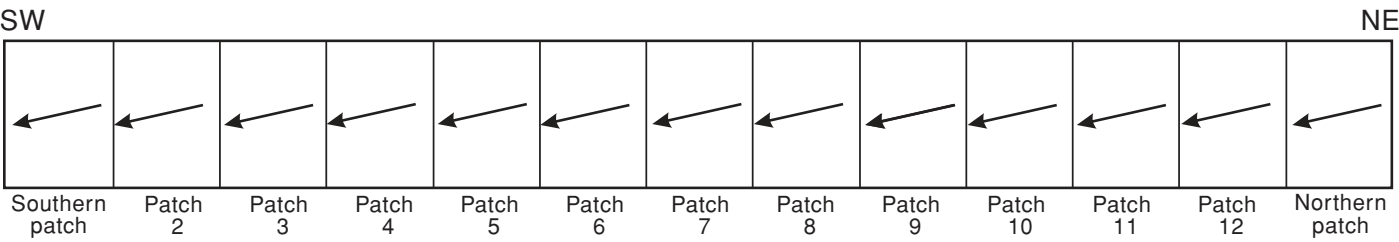

Fig. 4. The tapered-displacement Wairarapa Fault still has the listric shape and consists of five segment in the dip direction as shown in fig. 3, but each segment of the Wairarapa Fault is subdivided into 13 equal-sized, rectangular patches along the strike direction and the slip is linearly tapered from a maximum of $12 \mathrm{~m}$ horizontal displacement and $3 \mathrm{~m}$ vertical displacement at the center to $1.71 \mathrm{~m}$ and $0.43 \mathrm{~m}$ at the ends (table III). The arrow represents the rake direction.

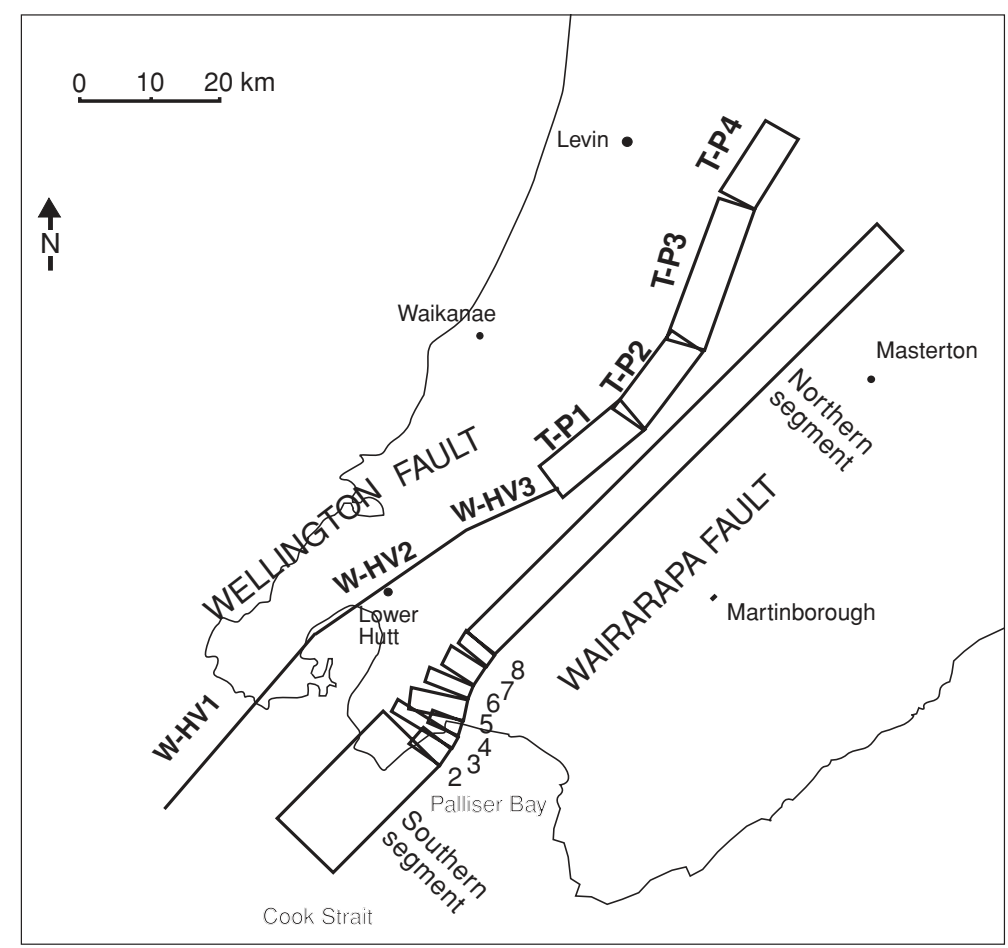

Fig. 5. The surface projection of the Wairarapa Fault, and the W-HV and T-P segments of the Wellington Fault. The flexed Wairarapa Fault Model is approximated by nine segments, whose dips decrease from $75^{\circ}$ at the northern end to $60^{\circ}$ at the southern end (Darby and Beanland, 1992). Although the northern segment has the same depth as the southern segment, its surface projection is narrower.

face with a variable dip so that the top edge follows the surface trace interpolated between the mapped offset segments. For simplicity, this flexed model is approximated by a series of planes. The dips of the planes decrease from $75^{\circ}$ at the northeastern end to $60^{\circ}$ at the southwestern end (fig. 5; table I). As the flexed Wairarapa Fault Model can create huge vertical 
Table II. Horizontal and vertical displacements on the 13 patches along the strike direction in the tapereddisplacement Wairarapa Fault Model.

\begin{tabular}{|c|c|c|c|c|c|c|c|c|c|c|c|c|c|}
\hline Displacement & $\begin{array}{l}\text { Southern } \\
\text { patch }\end{array}$ & $\begin{array}{l}\text { Patch } \\
2\end{array}$ & $\begin{array}{c}\text { Patch } \\
3\end{array}$ & $\begin{array}{c}\text { Patch } \\
4\end{array}$ & $\begin{array}{l}\text { Patch } \\
5\end{array}$ & $\begin{array}{l}\text { Patch } \\
6\end{array}$ & $\begin{array}{l}\text { Central } \\
\text { patch }\end{array}$ & $\begin{array}{l}\text { Patch } \\
8\end{array}$ & $\begin{array}{l}\text { Patch } \\
9\end{array}$ & $\begin{array}{l}\text { Patch } \\
10\end{array}$ & $\begin{array}{l}\text { Patch } \\
11\end{array}$ & $\begin{array}{c}\text { Patch } \\
12\end{array}$ & $\begin{array}{l}\text { Northern } \\
\text { patch }\end{array}$ \\
\hline & & & & & & & & & & & & & \\
\hline & 0.45 & 86 & 1.29 & 11 & 2.14 & 2.57 & 3 & 2.57 & 2.14 & 1.71 & 1.29 & 0.86 & 0.43 \\
\hline
\end{tabular}

Table III. Parameters about W-HV segment and T-P segment of the Wellington Fault for calculating $\Delta$ CFS (modified from Berryman and Van Dissen, 2001, and personal communication with Russ J. Van Dissen).

\begin{tabular}{ccllclccc}
\hline \hline \multirow{2}{*}{$\begin{array}{c}\text { Fault } \\
\text { segment }\end{array}$} & $\begin{array}{c}\text { Section } \\
\text { No. }\end{array}$ & $\begin{array}{l}\text { Length } \\
(\mathrm{km})\end{array}$ & $\begin{array}{l}\text { Width } \\
(\mathrm{km})\end{array}$ & $\begin{array}{c}\text { Strike } \\
\left({ }^{\circ}\right)\end{array}$ & $\begin{array}{l}\text { Dip } \\
\left({ }^{\circ}\right)\end{array}$ & $\begin{array}{c}\text { Fault } \\
\text { rake }\end{array}$ & \multicolumn{2}{c}{ Central location } \\
\hline \multirow{3}{*}{ W-HV } & W-HV1 & 32 & 20 & 40 & 90 & $180\left(^{*}\right)$ & -41.377 & 174.663 \\
& W-HV2 & 27 & 20 & 52 & 90 & 180 & -41.194 & 174.913 \\
& W-HV3 & 16 & 20 & 65 & 90 & 180 & -41.092 & 175.121 \\
\hline \multirow{4}{*}{ T-P } & T-P1 & 15 & 21.5 & 50 & 70 & 180 & -41.01 & 175.25 \\
& T-P2 & 14 & 21.5 & 37 & 70 & 180 & -40.92 & 175.359 \\
& T-P3 & 22 & 21.5 & 20 & 70 & 180 & -40.776 & 175.443 \\
& T-P4 & 12 & 21.5 & 32 & 70 & 180 & -40.633 & 175.523 \\
\hline
\end{tabular}

(*) $180^{\circ}$ rake means right-lateral.

displacement at the Turakirae Head, it is also a reasonable model for consideration.

In conclusion, three Wairarapa Fault models are assumed. They are the listric fault, the tapered-displacement fault and the flexed fault (table I). As there is no other geophysical evidence on the Wairarapa Fault available at present, its deep tectonics used in the above models may be far from the actual situations. The three models only reflect our present understanding about the Wairarapa Fault.

\subsection{The Wellington Fault}

The Wellington Fault can be divided into three rupture segments (Berryman and Van Dissen, 2001). The Wellington-Hutt Valley (WHV) segment is the southern-most $75 \mathrm{~km}$ long part of the fault, from offshore in Cook Strait to the $c a .2 \mathrm{~km}$ wide right side-step at Kaitoke at the southern end of the Tararua Ranges. The next part of the fault has been called the Tararua-Putara (T-P) Segment with a 62-65 km length. The distance from the northern boundary of T-P rupture segment to Woodville at the northern end of the Pahiatua section of the fault is only about 30-35 km, so the Woodville (W) Segment is expected to extend perhaps an equal distance further north. As the northeastern end of the $\mathrm{W}$ segment is not well defined, only the W-HV segment and the T-P segment are considered in this study. The W-HV segment and the T-P segment are divided into three and four sub-sections, based on the difference of their strikes (table III and fig. 3).

We know little about the deep tectonics of the Wellington Fault. A vertical dip for the W-H segment and a $70^{\circ}$ dip to the northwest for the T-P segment are assumed (Russ J. Van Dissen, personal communication) (fig. 2a,b). Robinson (1986) estimated that the range for seismogenic crustal thickness is between 15 to $30 \mathrm{~km}$ in the Wellington region. The cross section of seismicity indicates that the cluster of events NW of the Kapiti Island extends to a depth of about $20 \mathrm{~km}$, but it is difficult to characterise the seismicity SE of Kapiti Island as being on the subduction interface, or on the overlying faults (Robinson and Benites, 1996). The seismogenic depths are taken as $12.5 \mathrm{~km}$ both in California, 
U.S.A. and North Anatonia, Turkey (Jaume and Sykes, 1996; Stein et al., 1997), but Toda et al. (1998) used $20 \mathrm{~km}$ as the depth of faulting in the Osaka-Kobe region, Japan. It is appropriate to assume $20 \mathrm{~km}$ as the depth to bottom of the Wellington Fault or the thickness of seismogenic layer, as the deep tectonics of the Wellington region is more similar to that of the Osaka-Kobe region, Japan, located above a plate subduction. In this case, the downdip width is $20 \mathrm{~km}$ for the $\mathrm{W}-\mathrm{H}$ segment and 21.5 $\mathrm{km}$ for the T-P segment (table III). Compared to the downdip width range of $20 \sim 25 \mathrm{~km}$ for all the faults above the plate interface in the Wellington region (Robinson and Benites, 1996), our assumption on the fault bottom depth can be accepted. The downdip extent of the faulting can affect the results of both the $\triangle \mathrm{CFS}$ and tectonic loading rates on the concerned fault, so a seismogenic depth of $15 \mathrm{~km}$ is also considered in the 4th part (conclusion and discussion) of the paper to assess the sensitivity of our model to seismogenic thickness.

\section{Results}

We use the program GNStress1_5, available from ftp.gns.cri.nz/pub/robinson/GNStress1_5/ GNStress1_5.exe (R. Robinson, personal communication, 2001) to calculate the $\triangle \mathrm{CFS}$ (using an average rigidity of $2.68 \times 10^{10} \mathrm{~N} \mathrm{~m}^{-2}$ ) which are rotated to any required orientation, and tectonic stress loading rate. The induced stress changes may be resolved onto some specified fault plane and rake to indicate whether events are retarded or promoted. The program GNStress1_5 has been used to study earthquake triggering in Hawke's Bay, NZ (McGinty and Darby, 2001).

The induced Coulomb Failure Stress (CFS) is calculated using

$$
\Delta \mathrm{CFS}=\Delta \tau_{s}+\mu\left(\Delta \sigma_{n}+\Delta P\right)
$$

where $\Delta \tau_{s}$ is the induced changes in shear stress, $\mu$ is the dry coefficient of friction, $\Delta \sigma_{n}$ is the induced change in normal stress, and $\Delta P$ is the change in pore pressure given by

$$
\Delta P=-\beta / 3\left(\Sigma \Delta \tau_{i i}\right)
$$

where $\beta$ is Skempton's coefficient. A value of 0.75 for the coefficient of friction is normal, as observed in the German Continental Deep Drilling Project (KTB) ultra deep borehole (0.7) and deduced from induced seismicity in oil fields (0.8) (Raleigh et al., 1972; Brudy et al., 1997). $\Delta P$ is calculated with $\beta=0.5$. Reasonable variations in $\mu$ or $\beta$ have little effect on the values of induced CFS.

The $\triangle \mathrm{CFSs}$ due to the occurrence of the 1855 Wairarapa earthquake were calculated on rectangular surfaces representing the different sections of the W-HV segment and T-P segment of the Wellington Fault of our interest, with centres at mid-seismogenic depths of 10 $\mathrm{km}$. Since we lack hypocentral depths for strong earthquakes in the Wellington region, we sample stress in the central part of seismogenic layer in the same way that Harris and Simpson (1992), Simpson and Reasenberg (1994) and Stein et al. (1997) have done. If $\Delta \mathrm{CFS}>0$ (positive $\Delta \mathrm{CFS}$ ), it means that the 1855 Wairarapa earthquake brought a Wellington fault event on the W-HV segment or T-P segment closer to failure. If $\triangle \mathrm{CFS}<0$ (negative $\triangle \mathrm{CFS}$ ), the 1855 Wairarapa earthquake sent a Wellington fault event on the W-HV segment or T-P segment farther away from failure and into a stress shadow.

The listric Wairarapa Fault - Negative $\triangle \mathrm{CFS}$ is dominant on both the W-HV and T-P segments (fig. 6a,b), except for the offshore part in Cook Strait of W-HV1 section and T-P3 section. The results also demonstrate that the $\triangle \mathrm{CFS}$ is highly dependent on the orientation of the fault. As a Wellington fault event is assumed to usually rupture either the entire WHV segment or the entire T-P segment (Berryman and Van Dissen, 2001), it is reasonable to give an averaged $\triangle \mathrm{CFS}$ for the segment by considering all the sections in the segment. The $\Delta$ CFSs are resolved to the W-HV segment and T-P segment at the mid-seismogenic depths of $10 \mathrm{~km}$ and in their rakes (fig. 6b). The average $\triangle \mathrm{CFSs}$ at the depth of $10 \mathrm{~km}$ are about - 20.4 bar for the W-HV segment and -8.5 bar for the T-P segment. The values show that the occurrence of the $M 8.21855$ Wairarapa earthquake caused a stress shadow on 

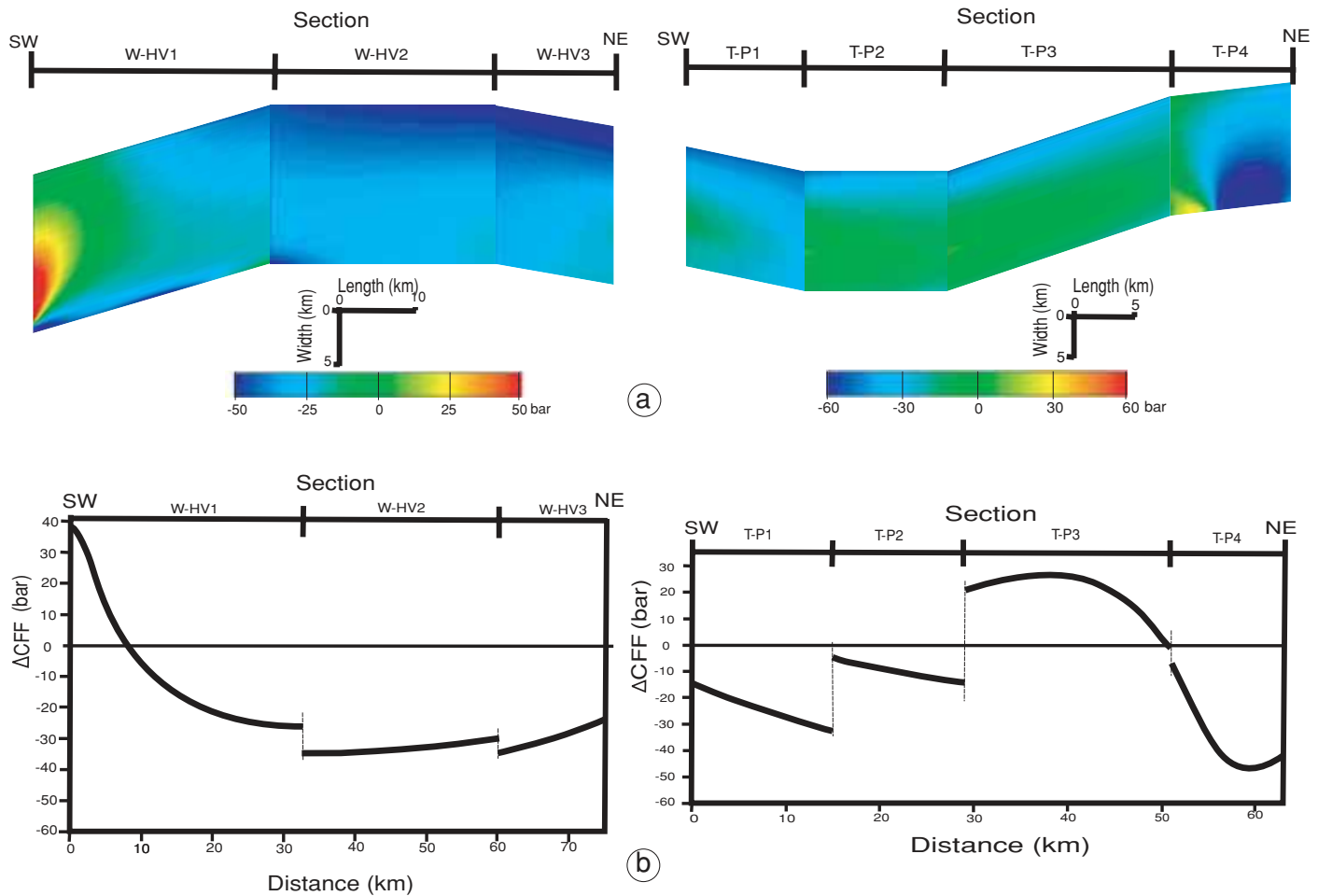

Fig. 6a,b. The distribution of $\triangle$ CFSs on the Wellington Fault for the listric Wairarapa Fault Model. a) The calculated stress changes were resolved onto the rectangular surfaces, representing the fault planes of the W-HV segment and the T-P segment of our interest. b) The $\Delta$ CFSs is resolved to the W-HV segment and T-P segment at the mid-seismogenic depths of $10 \mathrm{~km}$. Since we lack hypocentral depths for the strong earthquakes in the Wellington region, we sample stress in the central part of the seismogenic layer in a way as Harris and Simpson (1992), Simpson and Reasenberg (1994) and Stein et al. (1997) have ever done.

the two segments and potentially reduced their seismic hazard.

The tectonic loading rate for the W-HV and T-P segments can be approximated from fault long-term slip rates (Simpson and Reasenberg, 1994; Deng and Sykes, 1997). For the W-HV and T-P segments that have been relaxed by a stress shadow, estimates of the tectonic loading rate allow us to calculate how long it will take the fault segments to return to its state of loading before the 1855 Wairarapa earthquake. During the recovery period, we would not anticipate large earthquakes on the fault segments, assuming that there is no influence from other sources, the earthquake did not alter the failure threshold and failure is a fairly deterministic process.

There are two approaches to calculate the tectonic loading rate. Simpson and Reasenberg (1994) proposed a deep slip model, in which it is assumed that only the seismogenic layer is moving in stick-slip fashion. The deeper layers are moving at steady rates approximated by the long-term slip rates and transfer stress to the seismogenic portion of the fault. The long-term slip rates are assigned to dislocations extending from 20 - to $100-\mathrm{km}$ depth under the fault segments. Then, the $\triangle \mathrm{CFS}$ calculation technique is used again to look at the stress changes at the seismogenic layer. Deng and Sykes (1997) used 
a virtual dislocation model to approximate the tectonic loading rates, which only assume the seismogenic portion of the fault to move. The long-term slip rates are assigned to dislocations extending from 0 - to $20-\mathrm{km}$ depth. Both approaches reveal almost the same results (R. Simpson, personal communication). Although in reality the W-HV and T-P segments probably intersect the underlying subduction interface and the upper crustal faults may only conceptually slip at great depths, it does not affect calculation of the tectonic loading rates.

The average dextral slip rate estimates for the W-HV segment and the W segment, north of the T-P segment, are 6-7.6 mm/yr and 4.6$7.2 \mathrm{~mm} / \mathrm{yr}$, respectively (Van Dissen and Berryman, 1996; Berryman and Van Dissen, 2001).
As the T-P segment is mainly located in the Tararua Range, it is difficult to collect slip-rate data on the segment. The fault slip rate is assigned as $4.6-7.6 \mathrm{~mm} / \mathrm{yr}$ from the minimum to the maximum in both $\mathrm{W}-\mathrm{HV}$ segment in its south and W segment in its north. The tectonic stress loading rates per decade for the $\mathrm{W}$ $\mathrm{HV}$ and T-P segments are $0.34-0.43$ bar and 0.26-0.43 bar. By applying the Coulomb-failure model (e.g., Simpson and Reasenberg, 1994), the average retarded years can be approximated as 470-600 years for the W-HV segment and 200-330 years for the T-P segment (table IV). Although Rate-and-State ( $\mathrm{R} \& \mathrm{~S}$ ) friction model was also used to calculate the retardation or advancement years, both the Coulomb and R \& $\mathrm{S}$ models create similar results when the time to

Table IV. The average $\Delta$ CFSs and their influence on the seismic risk.

\begin{tabular}{|c|c|c|c|c|c|c|}
\hline \multirow{2}{*}{\multicolumn{2}{|c|}{$\begin{array}{l}\text { Fault segments and } \\
\text { sections on } \\
\text { Wellington Fault }\end{array}$}} & \multicolumn{2}{|c|}{$\begin{array}{l}\text { The average } \Delta \text { CFS (bars), } \\
\text { taking the lengths as weights }\end{array}$} & \multirow[t]{2}{*}{$\begin{array}{l}\text { Slip rate } \\
(\mathrm{mm} / \mathrm{yr})\end{array}$} & \multirow[t]{3}{*}{$\begin{array}{l}\text { Bars per } \\
\text { decade }\end{array}$} & \multirow[t]{2}{*}{ Retarded years } \\
\hline & & Section & Segment & & & \\
\hline \multicolumn{6}{|c|}{ Listric Wairarapa Fault } & \\
\hline W-HV & $\begin{array}{l}\text { W-HV1 } \\
\text { W-HV2 } \\
\text { W-HV3 }\end{array}$ & $\begin{array}{l}-8.1 \\
-31.4 \\
-30.2\end{array}$ & -20.4 & $6.0-7.6$ & $0.34-0.43$ & $470-600$ \\
\hline T-P & $\begin{array}{l}\text { T-P1 } \\
\text { T-P2 } \\
\text { T-P3 } \\
\text { T-P4 }\end{array}$ & $\begin{array}{l}-24.3 \\
-10 \\
20.1 \\
-37.1\end{array}$ & -8.5 & 4.6-7.6 & $0.26-0.43$ & $200-330$ \\
\hline \multicolumn{7}{|c|}{ The tapered-displacement Wairarapa Fault } \\
\hline W-HV & $\begin{array}{l}\text { W-HV1 } \\
\text { W-HV2 } \\
\text { W-HV3 }\end{array}$ & $\begin{array}{l}-1.9 \\
-11.7 \\
-37.0\end{array}$ & -12.9 & $6.0-7.6$ & $0.34-0.43$ & $300-380$ \\
\hline T-P & $\begin{array}{l}\text { T-P1 } \\
\text { T-P2 } \\
\text { T-P3 } \\
\text { T-P4 }\end{array}$ & $\begin{array}{l}-31.6 \\
-8.4 \\
8.1 \\
-8.8\end{array}$ & -8.2 & 4.6-7.6 & $0.26-0.43$ & $190-320$ \\
\hline \multicolumn{7}{|c|}{ The flexed Wairarapa Fault } \\
\hline W-HV & $\begin{array}{l}\text { W-HV1 } \\
\text { W-HV2 } \\
\text { W-HV3 }\end{array}$ & $\begin{aligned} & 8.2 \\
- & 34.8 \\
- & 46.8\end{aligned}$ & -19.0 & $6.0-7.6$ & $0.34-0.43$ & $440-560$ \\
\hline T-P & $\begin{array}{l}\text { T-P1 } \\
\text { T-P2 } \\
\text { T-P3 } \\
\text { T-P4 }\end{array}$ & $\begin{array}{l}-42.1 \\
-28.1 \\
0.6 \\
-19.3\end{array}$ & -19.7 & 4.6-7.6 & $0.26-0.43$ & $460-760$ \\
\hline
\end{tabular}




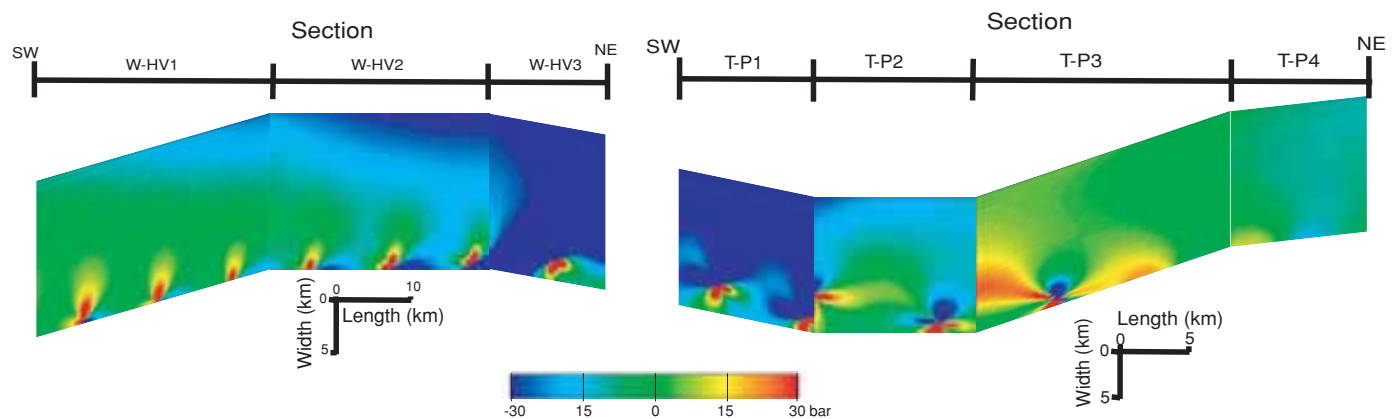

(a)
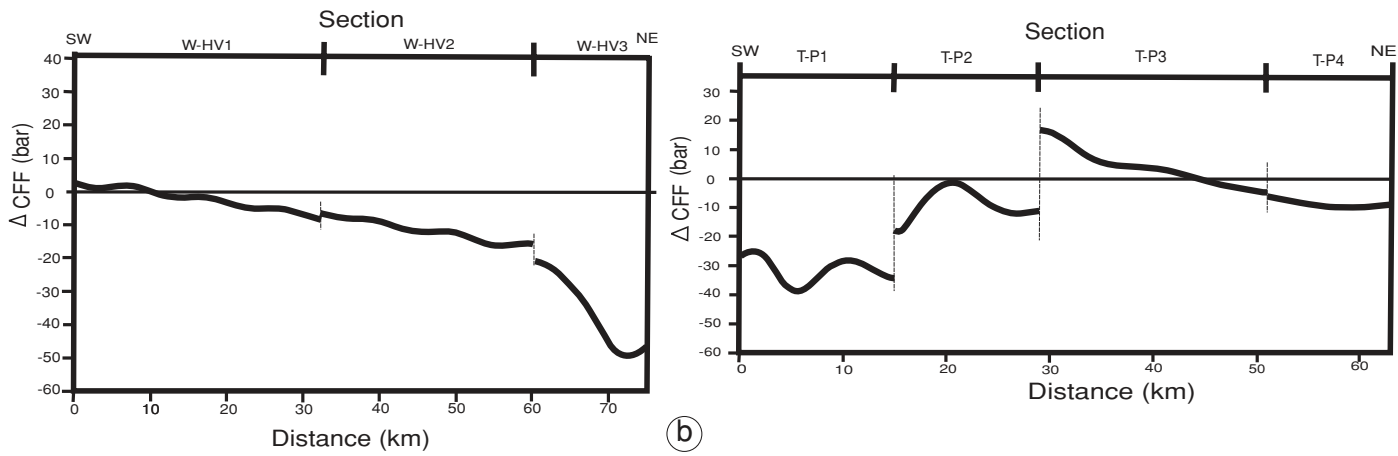

Fig. 7a,b. The distribution of $\Delta$ CFSs for the tapered-displacement Wairarapa Fault. a) The distribution of $\Delta$ CFSs on the fault planes of the W-HV and T-P segments. b) The distribution of $\Delta$ CFSs at the mid-seismogenic depth of $10 \mathrm{~km}$.

failure is long enough. Besides, the $\mathrm{R} \& \mathrm{~S}$ assumptions are based on laboratory experiments and the parameters in the model have a large uncertainty (Dieterich, 1994; Harris and Simpson, 1998; Stein, 1999).

The tapered-displacement Wairarapa FaultThe distribution of the $\triangle \mathrm{CFS}$ for this fault model is also characterised by negative values on the W-HV and T-P segments (fig. 7a,b), except for the offshore part in Cook Strait of the W-HV1 section and the northern part of the T-P3 section. As each of the five planar segments of the listric Wairarapa Fault is divided into 13 equal-sized, rectangular patches along strike, the boundary effect of each patch is partly reflected on the fig. 7a,b. The average $\Delta$ CFSs on the W-HV segment and T-P segment at the mid-seismogenic depth of $10 \mathrm{~km}$ are -12.9 bar and -8.2 bar (table IV and fig. 7b). The values are smaller than those for the listric Wairarapa fault model, but still suggest that the occurrence of the $M 8.21855$ Wairarapa earthquake caused a stress shadow on the two segments and potentially reduced their seismic hazard. Based on the tectonic stress loadings per decade and $\triangle \mathrm{CFSs}$ on the $\mathrm{W}-\mathrm{HV}$ and T-P segments, the average retarded years are approximated as 300-380 years for the W-HV segment and 190-320 years for the T-P segment by applying Coulomb-failure model (table IV).

The flexed Wairarapa Fault - The distribution of $\triangle \mathrm{CFSs}$ on the W-HV and T-P segments is shown on fig. $8 \mathrm{a}, \mathrm{b}$. The difference from the above two fault models is that most of the WHV1 section has positive $\triangle \mathrm{CFS}$. If the W-HV1 section ruptured independently, the occurrence 

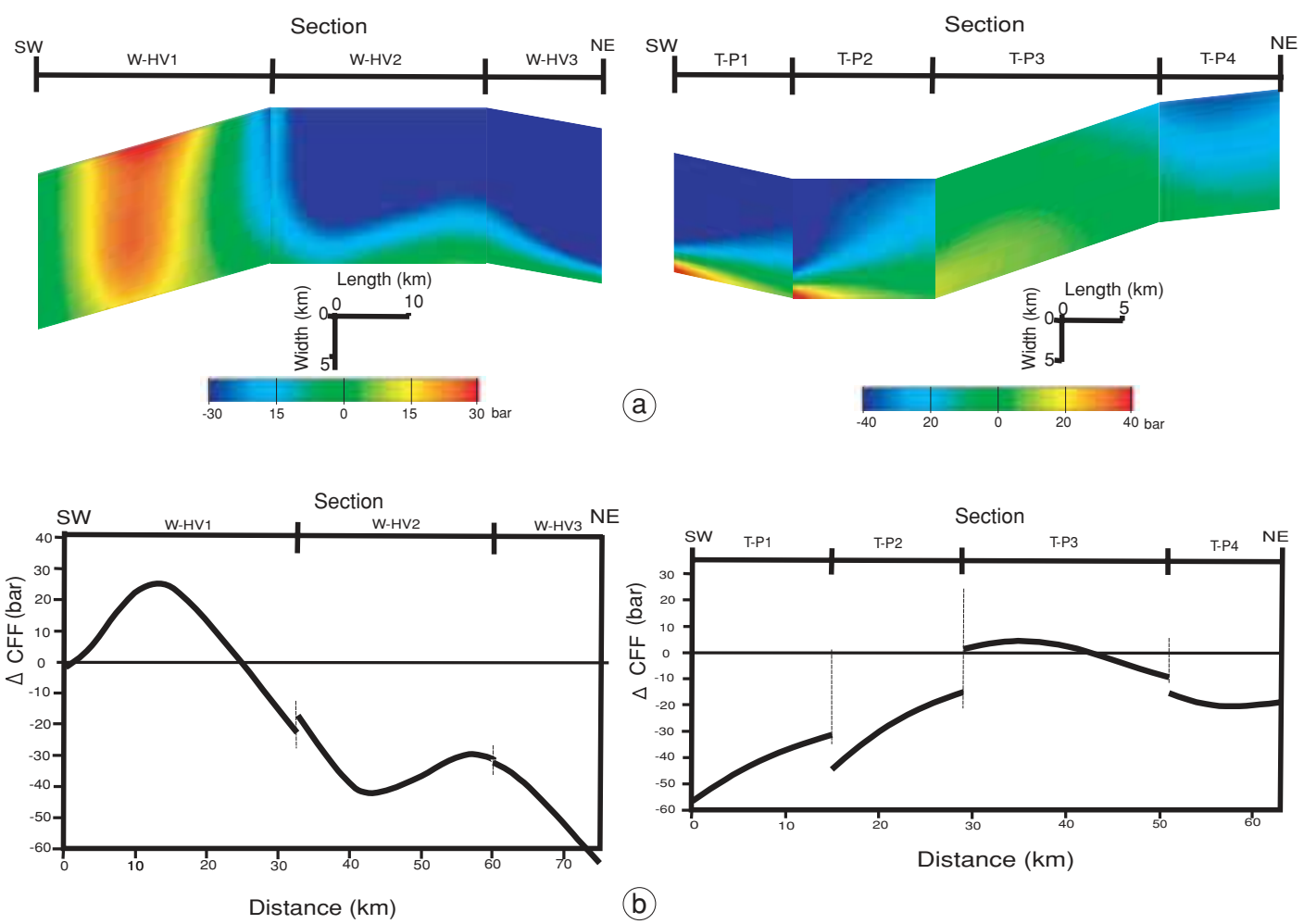

Fig. 8a,b. The distribution of $\triangle \mathrm{CFSs}$ for the flexed Wairarapa Fault. a) The distribution of $\Delta$ CFSs on the fault planes of the W-HV and T-P segments. b) The distribution of $\Delta$ CFSs at the mid-seismogenic depths of $10 \mathrm{~km}$.

of the 1855 Wairarapa earthquake might advance a rupture event on the W-HV1 section. The average $\triangle \mathrm{CFSs}$ on the W-HV segment and T-P segment are -19.0 bar and -19.7 bar (table IV and fig. 8b). The average retarded years are approximated as 440-560 years for the W-HV segment and 460-760 years for the T-P segment.

\section{Discussion and conclusions}

Considering uncertainties on our knowledge of the Wairarapa Fault, listric, tapered-displacement and flexed Wairarapa Fault models are assumed to estimate the $\triangle \mathrm{CFSs}$ on the W-HV and T-P segments caused by the 1855 Wairarapa earthquake. The results suggest that the W-HV segment and the T-P segment could be stable in at least the future 300 years and 190 years respectively, for these periods should be needed to accumulate the stress released by the $M 8.2$ Wairarapa earthquake, assuming that there is no influence from other sources, the earthquake did not alter the failure threshold and failure is a fairly deterministic process. The influence on the W-HV and T-P segments of the Wellington Fault from the $1855, M 8.2$ Wairarapa earthquake is significant, especially considering that the average fault rupture recurrence interval on the Wellington Fault is about 500-770 years (Van Dissen and Berryman, 1996).

Fault interaction demonstrates that the event intervals can be variable. Four events in the W segment have been identified (Berryman and Van Dissen, 2001). The Most recent Faulting 
Event (MFE), the Penultimate Faulting Event (PFE), the third event and the fourth event in the W segment are 1860-1670 A.D., 1160-890 A.D., 150-400 B.C. and 1960-2130 B.C. respectively. The intervals between MFE and PFE, and between the $3 \mathrm{rd}$ and 4 th events are $740 \pm 230$ years and $1975 \pm 375$ years respectively. Thus the variation of event intervals can be as much as 1235 years. Compared to this value, the retardation in years for events on the W-HV segment and T-P segment are acceptable.

Although our modelling suggests that the 1855 Wairarapa earthquake may retard events on the Wellington Fault, Robinson and Benites (1996) pointed out that mutual enhancement occurs between the two segments of the Wellington Fault that almost join end to end. If an event, for example, happens in the $\mathrm{W}$ segment of Wellington Fault, it will advance the occurrence of earthquake in the T-P segment. It, in turn, will advance earthquakes on the W-HV segment.

Width, strike, dip, and rake of fault have effects on the $\triangle$ CFS. For example, if $15 \mathrm{~km}$ is used as the depth to the bottom of the Wellington Fault and the listric Wairarapa Fault Model is applied, the average $\Delta$ CFSs on the W$\mathrm{HV}$ and T-P segments at $7.5 \mathrm{~km}$ depth become -25.8 bar and -10.8 bar. The tectonic loading rates per decade on the $\mathrm{W}-\mathrm{HV}$ and T-P segments are respectively $0.45-0.57$ bar and 0.32 0.54 at the central part of seismogenic layer. The retarded years can be approximated as 450570 years on the W-HV segment and 200-340 years on the T-P segment. Compared to the retarded years of 470-600 years on the W-HV segment and 200-330 years on the T-P segment when $20 \mathrm{~km}$ is assumed as the seismogenic thickness (table IV), it can be concluded that when the seismogenic thickness of the Wellington Fault has a reasonable difference, it should not change the basic indications of the $\triangle \mathrm{CFS}$. The situation when the W-HV segment has the same fault dip of $70^{\circ}$ as the T-P segment is also considered. The average $\triangle \mathrm{CFS}$ on the $\mathrm{W}$ HV segment becomes -33.1 bar, when the listric Wairarapa Fault Model is assumed, and the tectonic loading rate per decade is $0.31-0.40$ bar. The retarded years can be approximated as 830-1070 years. Besides, to have a component of dip-slip is reasonable in some sections of both W-HV segment and T-P segment. We use the geological slip-rate of faults to calculate the loading rate, but the actual strain or stress accumulation rate on the Wellington Fault is changeable. Although these uncertainties in the model assumptions may not change the basic indication as to the possible effects of the 1855 Wairarapa earthquake on the Wellington Fault, the retarded years highly depend on these assumptions. It means that our modelling results can be used only as an order-of-magnitude indication. They are not constrained enough to be used as a prediction.

With our present understanding of the Wellington and Wairarapa faults, it can be concluded that the $1855, M 8.2$ Wairarapa earthquake has retarded earthquake occurrence on the W-HV segment and the T-P segment of the Wellington Fault. Thus the seismic hazard in the Wellington region may be over-estimated (Stirling et al., 1998).

\section{Acknowledgements}

The work was done by using GNStress1_5, provided by Dr. Russell Robinson, when I was a visitor at GNS (Institute of Geological and Nuclear Sciences), New Zealand, and supported by the China Scholarship Council and National Natural Science Foundation of China (40274008). Figure 1a,b, showing the tectonic framework of the Wellington region, is provided by Dr. Kelvin R. Berryman. My thanks to Dick Beetham, Russell Robinson, Rafael Benites, Russ. J. Van Dissen, Colin Mazengarb (GNS), Ruth A. Harris and Robert W. Simpson (USGS). I also thank Russ Van Dissen and an anonymous reviewer for their constructive comments.

\section{REFERENCES}

BerRyMAN, K. and R.J. VAN DisSEN (2001): Recent rupture of the Tararua section of the Wellington Fault and relationships to other fault sections and rupture segments, EQC Res. Rep. 97/248.

Brudy, M., M.D. Zoback, K. Fuchs, F. Rummel and J. BAUMGARTNER (1997): Estimation of the complete stress 
tensor to $8 \mathrm{~km}$ depth in the KTB scientific drill holes: implications for crustal strength, J. Geophys. Res., 102, $18,453-18,475$.

DARBY, D.J and S. BEANLAND (1992): Possible source models for the 1855 Wairarapa earthquake, New Zealand, J. Geophys. Res., 97, 12,375-12,389.

DenG, J. and L.R. SYKes (1997): Evolution of the stress field in Southern California and triggering of moderate-size earthquakes: a 200-year perspective, J. Geophys. Res., 102, 9859-9886.

DiETERICH, J. (1994): A constitute law for rate of earthquake production and its application to earthquake clustering, J. Geophys. Res., 99, 2601-2618.

EllsworTH, W. (1990): Earthquake history, 1769-1989, in The San Andreas Fault System, California, edited by R. Wallace, U.S. Geol. Surv. Prof. Pap. 1515, chapter 6, 153-188.

GraPES, R.H. and G. DownEs (1997): The 1855 Wairarapa, New Zealand, earthquake - Analysis of historical data, Bull. N.Z. Nat. Soc. Earthquake Eng., 30 (4), 271-368.

Grapes, R.H. and H.W. WELLMAN (1988): The Wairarapa Fault, Publication No.4, Research School of Earth Sciences, Geology Board of Studies, Victoria University of Wellington, Wellington, New Zealand.

HARRIS, R.A. (1998): Introduction to special session: stress triggers, stress shadows, and implications for seismic hazard, J. Geophys. Res., 103, 24,347-24,358.

HARRIS, R.A. and R.W. SIMPSON (1992): Changes in static stress on Southern California faults after the 1992 Landers earthquake, Nature, 360, 251-254.

HARRIS, R.A. and R.W. SIMPSON (1998): Suppression of large earthquakes by stress shadows: a comparison of Coulomb and rate-and-state, J. Geophys. Res., 103, 24,439-24,451.

JAUME, S.C. and L.R. SyKES (1996): Evolution of moderate seismicity in the San Francisco Bay region, 1850 to 1993: seismicity changes related to the occurrence of large and great earthquakes, J. Geophys. Res., 101, 765-789.

KING, G.C.P., R.S. STEIN and J. LIN (1994): Static stress changes and the triggering of earthquakes, Bull. Seismol. Soc. Am., 84, 935-953.

McCAlPIN, J. and S.P. NishenKo (1996): Holocene plaeoseismicity, temporal clustering, and probabilities of future large $(M>7)$ earthquake on the Wasatch Fault Zone, Utah, J. Geophys. Res., 101 (B3), 62336253.

MCGinTY, P. and D. DARBY (2001): Earthquake triggering in the Hawke's Bay, New Zealand, region from 1931 to
1934 as inferred from elastic dislocation and static stress modeling, J. Geophys. Res., 106 (B11), 26,59326,604 .

Raleigh, C.B., J.H. Healy and J.D. Bredehoeft (1972): Faulting and crustal stength at Rangely, Colorado, in Flow and Fracture of Rock, edited by H.C. HEARD, I. Y. Borg, N.L. CARTER and C.B. Raleigh, Geophys. Monogr. Ser. (AGU, Washington, D.C.), vol. 16, 275284.

Robinson, R. (1986): Seismicity, strucuture, and tectonics of the Wellington region, New Zealand, Geophys. J. R. Astron. Soc., 87, 379-409.

Robinson, R. and R. BEnItes (1996): Synthetic seismicity models for the Welington region, New Zealand: implication for the temporal distribution of large events, $J$. Geophys. Res., 101, 27,833-27,844.

SieH, K.E., M. Stuiver and D. BRILlinger (1989): A more precise chronology of earthquakes produced by the San Andreas Fault in Southern California, J. Geophys. Res., 94, 603-623.

Simpson, R.W. and P.A. REASENBERG (1994): Earthquakeinduced static stress changes on Central California faults, in The Loma Prieta, California Earthquake of October 17, 1989 - Tectonic Processes and Models, edited by R.W. Simpson, U. S. Geol. Surv. Prof. Pap., 1550-F, F55-F89.

STEIN, R.S. (1999): The role of stress transfer in earthquake occurrence, Science, 402, 605-609.

Stein, R.S., G.C.P. KING and J. LIN (1994): Stress triggering of the $1994 M=6.7$ Northridge, California earthquake by its predecessors, Science, 265, 1432-1435.

Stein, R.S., A.A. BARKA and J.H. Dieterich (1997): Progressive failure on the North Anatolian Fault since 1939 by earthquake stress triggering, Geophys J. Int., 128, 594-604.

Stirling, M.W., S.G. Wesnousky and K.R. Berryman (1998): Probabilistic seismic hazard analysis of New Zealand, NZ J. Geol. Geophys., 41, 355-375.

Toda, S., R.S. Stein, P.A. ReAsEnberG and J.H. Dieterich (1998): Stress transferred by the $M_{w}=6.5$ Kobe, Japan, shock: effect on aftershocks and future earthquake probabilities, J. Geophys. Res., 103, 24,543-24,565.

VAN DisSEN, R.J. and K.R. BERRYMAN (1996): Surface rupture earthquakes over the last $\sim 1000$ years in the Wellington region, New Zealand, and implications for ground shaking hazard, J. Geophy Res., 101 (B3), 5999-6019.

Wellman, H.W. (1955): New Zealand Quaternary tectonics, Geol. Rundsch, 43, 248-257. 